\section{Maps by Order}

THE surveying and mapping of the British Isles are carried out by the Ordnance Survey. Despite an air of brisk efficiency, aided by a preponderance of army officers in senior positions, the survey has recently been the victim of some distinctly undisciplined shuffling in Whitehall. After 75 years in the care of the Ministry of Agriculture, the survey moved in 1965 to the Ministry of Land and Natural Resources, but had barely drawn breath before that ministry went into eclipse-it is at present in the process of dissolu. tion. The survey now has its third Minister in two years-the Minister of Housing and Local Government, Mr. Anthony Greenwood.

The survey's work does not seem to have been disturbed by this uncertainty. It is still a long way from completing the basic survey of Great Britain, but is making progress. Three basic scales are used; $1: 1,250$, $1: 2,500$ and $1: 10,560$ (6 in. to 1 mile). So far, however, maps of the whole country are available only at scales of 1 in. to 1 mile $(1: 63,360$ ) and 0.25 in. to 1 mile (1:250,000). Most urban areas are now mapped at scales of $1: 1,250$, but there is still much to do before the $1: 2,500$ plans of the counties are completed. Maps of mountains and moorland areas are also to be published, at the $1: 10,560$ scale, but here there is an enormous amount of work yet to be done. Another series has been undertaken during the past year, at 2.5 in. to 1 mile, and various archaeological and tourist maps are also available.

The survey is now more optimistic about finishing its task by 1980 . During his tenure of office, Mr. Fred Willey, Minister of Land and Natural Resources, authorized a 20 per cent increase in the staff of the survey over 10 years. Without this, reports the Director-General of the survey, Major-General Edge, in the annual report for $1965-66$ (H.M.S.O., $7 s .6 d$.), the job would hardly have been finished before the end of the century. Operations should also be easier when the survey moves to new headquarters in Southampton; this will bring together the work carried out in Esher and Chessington in Surrey and the drawing and reproduction department in Southampton.

If the move makes the work of the survey any less expensive, nobody will complain, as the budget is hardly chickenfeed. Expenditure last year was $\mathfrak{E 5 . 5}$ million, against receipts of $£ 1.7$ million. The survey has a staff of 4,548 , with 1,718 surveyors and 1,274 draughtsmen. The impression of a military machine is perhaps deceptive, as there are only 26 army officers on the staff, but most of them seem to be concentrated in the top executive positions.

\section{Qualified Success}

THE fourth French earth satellite launched from North Africa on Wednesday, February 8, and known as Diademe, secms to have been only a partial success. The device, of mass about $15 \mathrm{~kg}$, was found after launching to be in an orbit about the Earth with an apogee substantially lower $(1,340 \mathrm{~km})$ than that planned $(1,843 \mathrm{~km})$. It is therefore possible that the geodetic triangulation measurements which had been planned will now be difficult and even perhaps impossible. The original orbit was chosen so that the satellite would be simultaneously visible from three ground stations around the Mediterranean--at Colomb-Bechar in the Sahara, Saint Michele-de-Provence in France and at a station on the Gulf of Corinth. Lasers at each of the stations, together with Doppler measurements, were to have been used for triangulation. No doubt it will be possible to make good use of observations from pairs of stations and also from sky photography from several observatories beneath the orbit, but some precision will undoubtedly be lost.

Those responsible for the rocket programme were hoping earlier this week to repeat the triangulation experiments by launching a second satellite (and the fourth in the present series) into a somewhat higher orbit. The launching was due to take place on February 15 .

\section{Do Worms Learn?}

THE controversy about the mechanism by which planarian worms appear to learn by the ingestion of nucleic acids from other worms remains unresolved despite the deliberations of a conference at Michigan State University, East Lansing, last year (1966). Several papers at the conference were devoted to the factors which may directly or indirectly affect the results observed. There appear to be marked differences between the properties of planarian worms of different species-and there are as many as forty species in the United States. Much of the evidence which supports the notion of a chemical basis of learning has been based on experiments which demonstrate that an acquired response can survive regeneration, and a French participant at the conference described how different species of planaria differ in a mechanism of tissue renewal. Some do not regenerate at all. Others regenerate only at the front and others regenerate at any point along the axis. This obviously affects the way in which acquired information can be retained during regeneration. Among other animals to which the chemical basis of learning may be important are what have been described as the "micrometazoa"-hydra and so on. The conference also heard of experiments with the isolated insect ganglion, and one participant produced evidence which indicates that a single isolated ganglion in a cockroach can acquire an avoidance response. There is also histochemical evidence that may enable identification of the muscles and axons that are involved in information storage.

\section{Control of Haemoglobin Function}

\section{from a correspondent in Molecular Biology}

ONE of the most tantalizing problems in molecular biology concerns the nature of the haem-haem interactions in haemoglobin. It is well established that a conformational change occurs during oxygenation, but in spite of the detail in which the structure-at least of the oxygenated form-is known, how the change is controlled and transmitted remains obscure. The problem has the widest relevance to control mechanisms in enzyme systems.

Among the more promising approaches have been attempts to block selectively the coupling between the haems and the Bohr effect. Thus it has been found that normal human haemoglobin can under some circumstances be made to remain in the same confor- 